\title{
MODELLING THE SPATIAL AND TEMPORAL TRENDS OF CARBON ISOTOPE FRACTIONATION OF VOC MIXTURES IN THE UNSATURATED ZONE
}

\section{P. GAGANIS}

University of the Aegean, Department of Environmental Science, University Hill, Xenia Building, GR 81100 Mytilene, Greece

Selected from papers presented in $9^{\text {th }}$ *to whom all correspondence should be addressed International Conference on Environmental Tel: +48 6182934 34; Fax: 48618293400 Science and Technology (9CEST2005)

1-3 September 2005, Rhodes island, Greece

\begin{abstract}
The transport of volatile organic contaminant (VOC) mixtures in the unsaturated zone is typically controlled by a combination of transport (i.e., advection, dispersion, and diffusion) phenomena, phase change (i.e., volatilization, dissolution) and reaction processes (i.e., sorption, biodegradation). As revealed from field and laboratory studies, biodegradation is probably the most important attenuation mechanism of VOCs in the unsaturated zone since it transforms organic contaminants to harmless products. However, in field applications, it is usually difficult, time consuming, or expensive to distinguish and quantify biodegradation among the different natural phenomena and processes, such as diffusion, dispersion, volatilization and sorption, without the aid of numerical modeling.

Recent experimental studies showed large variations in space and time in the ${ }^{13} \mathrm{C} /{ }^{12} \mathrm{C}$ ratio for many organic compounds and suggested the possibility of using carbon isotope fractionation as a tool to assess biodegradation of organic contaminants in the unsaturated zone. The processes that were indicated to likely have the largest effect on the observed isotope ratio variations are (i) diffusion, which results in molecules with lighter isotopes to diffuse slightly faster than molecules with heavier isotopes, and (ii) biodegradation as a consequence of a preferential breakdown of the chemical bonds of the lighter isotopes.

This study used numerical modeling of VOC mixture transport in the unsaturated zone to quantify the contribution of diffusion and biodegradation to carbon isotope fractionation of individual compounds, and to evaluate the use of ${ }^{13} \mathrm{C} /{ }^{12} \mathrm{C}$ ratio as a possible tool to assess biodegradation of organic contaminants. The numerical model incorporated transport of carbon isotope fractions of selected organic compounds and used data from a controlled fuel source emplacement field experiment and parameters from laboratory-scale studies. Costeffective modelling of the transport and fate of volatile organic contaminant mixtures was realized with the use of the recently developed constituent averaging technique [1]. Results indicated that (i) both diffusion and biodegradation lead to enrichment in ${ }^{13} \mathrm{C}$ compared to the initial isotope ratio in locations within and close to the contaminant source, (ii) biodegradation lead to enrichment in ${ }^{13} \mathrm{C}$ while diffusion resulted in smaller ${ }^{13} \mathrm{C} /{ }^{12} \mathrm{C}$ ratio in locations further away from the source, and (iii) the above effect of both processes on the isotope ratio was increased as a function of time. Modelling results showed that the use of carbon isotope fractionation at the field represents a promising tool for assessing and possibly quantifying biodegradation of organic contaminants in the unsaturated zone.
\end{abstract}

KEYWORDS: VOCs, carbon isotope fractionation, biodegradation, organic contaminants, unsaturated zone 


\section{INTRODUCTION}

Mathematical models are routinely used to simulate fluid flow and solute transport in subsurface environments. The aim of these models is typically dual: First, to enhance our understanding of the problem by exploring the implications of making certain assumptions about the nature of hydrogeologic systems. Second, to predict the response of a real system under a set of naturally occurring conditions. Modelling flow and transport of volatile organic contaminants (VOCs) in the unsaturated zone is scientifically and technically challenging. The transport of volatile organic contaminant (VOC) mixtures in the unsaturated zone is typically controlled by a combination of transport (i.e., advection, dispersion, and diffusion) phenomena, and phase change (i.e., volatilization, dissolution) and reaction processes (i.e., sorption, and biodegradation). Unsaturated zone modeling becomes particularly complicated when the number of organic compounds in the pollution source increases, and interactions among phases, interfaces and chemical components are too significant to neglect.

As revealed from field [e.g., 2, 3] and laboratory [e.g., 4] studies, biodegradation is one of the most important attenuation mechanisms of VOCs in the unsaturated zone. However, in field applications, it is usually difficult, time consuming, or expensive to prove the occurrence, to distinguish and to quantify biodegradation among the different natural phenomena and processes, such as diffusion, dispersion, volatilization and sorption, without the aid of numerical modeling.

Recent experimental studies [e.g., 5] showed large variations in space and time in the ${ }^{13} \mathrm{C} /{ }^{12} \mathrm{C}$ ratio for many organic compounds and suggested the possibility of using carbon isotope fractionation as a tool to assess biodegradation of organic contaminants in the unsaturated zone. The processes that were indicated to likely have the largest effect on the observed isotope ratio variations are (i) diffusion, which results in molecules with lighter isotopes to diffuse slightly faster than molecules with heavier isotopes, and (ii) biodegradation as a consequence of a preferential breakdown of the chemical bonds of the lighter isotopes.

The present study used numerical modeling of VOC mixture transport in the unsaturated zone to quantify the contribution of diffusion and biodegradation to carbon isotope fractionation of individual compounds, and to evaluate the potential of using the ${ }^{13} \mathrm{C} /{ }^{12} \mathrm{C}$ ratio as a possible tool to assess biodegradation of organic contaminants in the unsaturated zone.

\section{HYDROGEOLOGIC MODEL DESCRIPTION}

The hydrogeologic model used in this study was similar to that described in [6], which was used to quantify the effects of the biodegradation process and to simulate a recent field scale experiment that involved transport and natural attenuation of a VOC mixture [5]. Simulations were performed using the numerical code MOFAT [7], which was adopted because it allows for a fairly flexible mathematical description of the boundary conditions and is able to account for the most important processes involved in the field experiment. The main features of the hydrogeological simulation model include [7]: (i) a three phase extension of the van Genuchten model to describe the relationships between phase permeabilities, saturations and pressures at locations where all three phases appear simultaneously; (ii) flow due to density differences and advective transport in the gas phase; (iii) equilibrium partitioning between the gas-aqueous, gas-NAPL, and aqueous-solid phases; and (iv) modeling of biodegradation, as a 1st order process. 
The original code was modified, in order to deal with the seasonal temperature variation at the field site. An external module was developed and coupled to the main code, which takes advantage of the available restart option at selected times for updating the fuel compound properties that are most sensitive to temperature according to literature expressions. The vapor pressure, Henry's law constant, and aqueous solubility were found to be the most sensitive parameters to temperature that also have the strongest effect on the transport process. These three parameters were treated as temperature dependent in the model, whereas the other parameters were assumed to remain constant throughout the experiment since they vary with temperature to a much lower extent. The relationships adopted here to express the temperature dependence of the vapor pressure and Henry's law constant for the compounds under consideration were those presented in [6]. The aqueous solubility values at different temperatures were calculated as the ratio of the vapor pressure to Henry's law constant. There are no quantitative data in the literature regarding the temperature dependence of biodegradation. However, the expected variations are probably small compared to the uncertainty in the values of the rate constant. Hence, biodegradation was treated in the model as being independent of temperature.

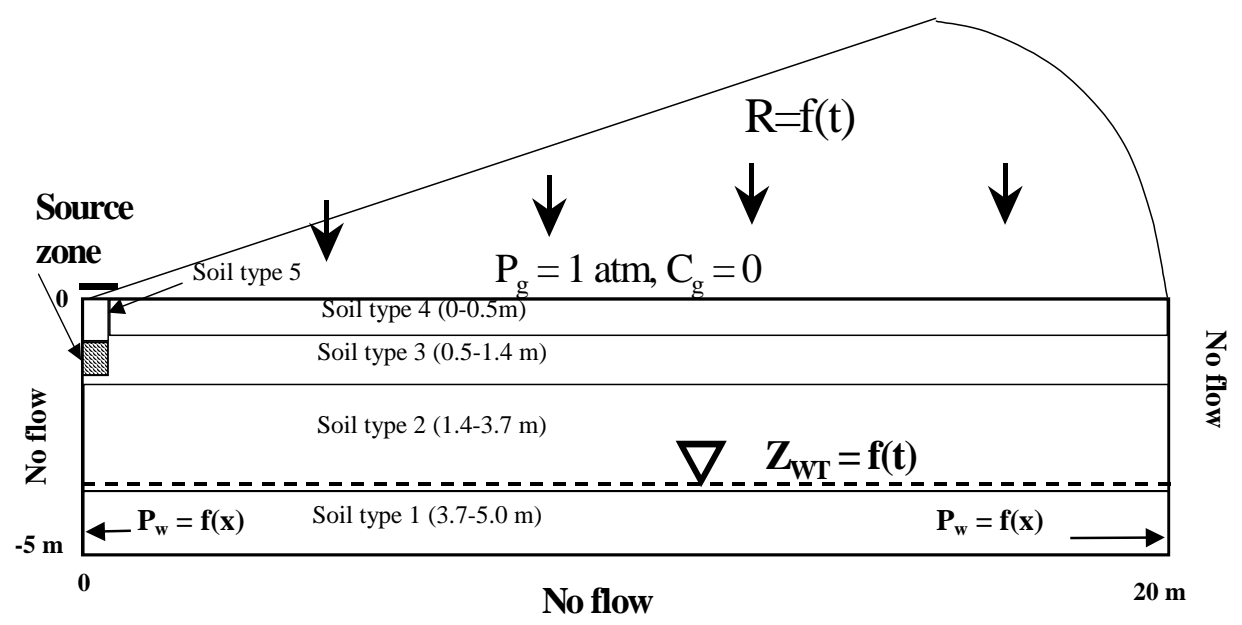

Figure 1. Model domain and boundary conditions

A two-dimensional model domain $(20 \mathrm{~m} \times 5 \mathrm{~m})$ and cylindrical coordinates were used for the simulations (Figure 1). The model domain consisted of 24 grid-blocks in the horizontal direction and 16 in the vertical direction and is composed of 5 homogeneous zones of different soil characteristics (Figure 1). The soil properties assigned to these five zones are based on measurements at the experimental site and are given in Table 1. In both directions, the model domain was discretized using a variable nodal spacing of $15-20 \mathrm{~cm}$ near the source zone (largest concentration gradient) that gradually increased as the outer boundaries are approached (up to $2 \mathrm{~m}$ in horizontal direction). This discretization scheme was found to provide a balance between accuracy of the calculations and savings in computational time. The boundary conditions for fluid flow and contaminant transport were (i) constant atmospheric pressure, time dependent groundwater recharge and constant concentration at the upper boundary $(C=0)$, (ii) temporal varying water table elevation according to field measurements, which implies a time variant specified hydraulic head below the water table, no flow conditions above the water table, and zero concentration gradient along the left and right boundary, and (iii) no flow and zero concentration gradient at the lower boundary (Figure 1). More details regarding the model and the parameters used can be found in [6]. 
Table 1: Property values assigned to the five soil types used in the model [6]

\begin{tabular}{cccccc}
\hline Property & $\begin{array}{c}\text { Soil } \\
\text { type } 1\end{array}$ & $\begin{array}{c}\text { Soil } \\
\text { type } 2\end{array}$ & $\begin{array}{c}\text { Soil } \\
\text { type 3 }\end{array}$ & $\begin{array}{c}\text { Soil } \\
\text { type } 4\end{array}$ & $\begin{array}{c}\text { Soil } \\
\text { type } 5\end{array}$ \\
\hline $\begin{array}{c}\text { Saturated hydraulic conductivity } \\
\left(\mathrm{m} \mathrm{d}^{-1}\right)\end{array}$ & 6.5 & 8.0 & 8.5 & 3.5 & 9.0 \\
$\begin{array}{c}\text { Porosity } \\
\text { Pon }\end{array}$ & 0.31 & 0.31 & 0.33 & 0.38 & 0.4
\end{tabular}

van Genuchten parameters

\begin{tabular}{cccccc}
$\alpha\left(m^{-1}\right)$ & 3.0 & 3.0 & 3.1 & 2.9 & 3.1 \\
$n$ & 2.8 & 2.9 & 2.98 & 1.85 & 2.9 \\
\hline
\end{tabular}

\section{MODELLING APPROACH}

The VOC mixture simulated was an artificial hydrocarbon mixture of 14 volatile and semivolatile compounds (BTX's, n-, iso- and cyclo-alkanes) similar to jet fuel. The fuel mixture composition and the physicochemical properties of the mixture compounds are shown in Table 2. Although the code adopted in this work (MOFAT) with the addition of the module for accounting for the temperature effects is able to simulate all the case specific important processes, it can only handle a maximum of 5 compounds, that is, only a fraction of the organic species (14) making up the simulated VOC mixture. The approach used to overcome this problem was to organize the mixture compounds into effective pseudospecies, that is, groups of actual species sharing similar property values. A grouping approach, termed constituent averaging technique [2], which suggested an objective function for determining case specific criteria for grouping individual compounds into "effective" species (composite constituents) and a new algorithm for estimating their effective thermodynamic properties, was adopted in the present work.

The present study focuses on simulating the variations in space and time in the ${ }^{13} \mathrm{C} /{ }^{12} \mathrm{C}$ ratio for Hexane. The processes that were indicated to likely have the largest effect on the observed isotope ratio variations are (i) diffusion, which results in molecules with lighter isotopes to diffuse slightly faster than molecules with heavier isotopes, and (ii) biodegradation as a consequence of a preferential breakdown of the chemical bonds of the lighter isotopes. To account for those effects, Hexane was simulated as three different individual compounds: (i) Hexane 12 with ${ }^{12} \mathrm{C}$ only (using diffusion coefficient and biodegradation rate values those estimated in [6]), (ii) Hexane13 with one atom of ${ }^{13} \mathrm{C}$ at the reactive position (using slightly smaller values for both diffusion coefficient and biodegradation rate from those estimated in [6]), and (iii) Hexane $13^{*}$ with the atom of ${ }^{13} \mathrm{C}$ somewhere else in the molecule (using slightly smaller value for the diffusion coefficient from that estimated in [6] and biodegradation rate value as estimated in [6]). Slower diffusion is expected for all molecules with heavy isotope at any position. However, slower biodegradation is only expected for Hexane13, since the initial microbe attack occurs at a terminal position and since shifts of the isotope ratio of the substrate reflect isotope fractionation associated with the initial step only [8]. The rest of the hydrocarbons in the mixture were simulated using a small number of composite constituents following the constituent averaging technique described in the previous section. In this case, the composite constituents were used to account for the effect of the mixture composition on the transport process of the selected individual compounds. The initial Hexane fractionation and the reduction in the diffusion coefficients and biodegradation rates assigned to either Hexane 13 or Hexane $13^{*}$ were estimated from the experimentally determined enrichment factor $[8,9]$ and relationships described in $[8,10]$. 
Table 2. Fuel mixture composition and physicochemical properties of compounds [6]

\begin{tabular}{|c|c|c|c|c|c|c|}
\hline Compound & $\begin{array}{l}\text { Weight } \\
\text { fraction } \\
\text { in } \\
\text { source } \\
(\%)\end{array}$ & $\begin{array}{c}\text { Vapor } \\
\text { Pressure } \\
25^{0} \mathrm{C} \\
{[\mathrm{kPa}]}\end{array}$ & $\begin{array}{l}\text { Henry's } \\
\text { law } \\
\text { constant } \\
{[-] 25^{\circ} \mathrm{C}}\end{array}$ & $\begin{array}{l}\log \\
K_{\text {ow }}\end{array}$ & $\begin{array}{c}\text { Water } \\
\text { solubility } \\
{\left[\mathrm{mg} \mathrm{l}^{-1}\right]} \\
25^{\circ} \mathrm{C}\end{array}$ & $\begin{array}{c}\text { Molecular } \\
\text { diffusion } \\
\text { coefficients in } \\
\text { the gas phase } \\
{\left[\mathrm{m}^{2} \mathrm{~d}^{-1}\right]}\end{array}$ \\
\hline Benzene & 1.02 & 12.672 & 0.217 & 2.13 & 1790 & 0.76 \\
\hline Toluene & 2.93 & 3.805 & 0.244 & 2.73 & 556 & 0.67 \\
\hline $\begin{array}{l}\text { m-Xylene } \\
1,2,4\end{array}$ & 4.57 & 1.106 & 0.26 & 3.20 & 158 & 0.62 \\
\hline $\begin{array}{l}\text { Trimethyl- } \\
\text { benzene }\end{array}$ & 10.99 & 0.271 & 0.28 & 3.78 & 57 & 0.57 \\
\hline Hexane & 7.26 & 20.20 & 68.58 & 4.11 & 9.5 & 0.64 \\
\hline Octane & 7.16 & 1.88 & 121.0 & 5.15 & 0.66 & 0.55 \\
\hline Decane & 15.99 & 0.175 & 197.85 & 6.25 & 0.052 & 0.49 \\
\hline Dodecane & 9.50 & 0.0157 & 296.77 & 7.24 & 0.0037 & 0.44 \\
\hline \multirow{3}{*}{$\begin{array}{l}\text { Methyl-cyclo- } \\
\text { pentane } \\
\text { Cyclo-pentane } \\
\text { Methyl- } \\
\text { cyclohexane }\end{array}$} & 5.79 & 18.4 & 14.8 & 3.37 & 42 & \multirow[t]{2}{*}{0.68} \\
\hline & 1.59 & 42.4 & 7.6 & 3.00 & 156 & \\
\hline & 10.23 & 6.13 & 17.6 & 3.61 & 14 & 0.63 \\
\hline \multirow{2}{*}{$\begin{array}{l}\text { Isooctane } \\
\text { 3-Methyl- } \\
\text { pentane }\end{array}$} & 15.36 & 6.56 & 123.6 & 4.20 & 2.44 & 0.55 \\
\hline & 7.45 & 25.3 & 68.6 & 3.60 & 12.8 & 0.65 \\
\hline CFC-113 & 0.16 & 44.67 & 14.20 & 3.16 & 170 & 0.63 \\
\hline
\end{tabular}

The mean initial $\delta^{13} \mathrm{C}$ of Hexane was experimentally estimated to be equal to $-30,5$ [9]. The initial concentration of subspecies Hexane12, Hexane13, and Hexane13* were calculated assuming that ${ }^{13} \mathrm{C}$ is equally distributed over all positions in the molecule.

The values of diffusion coefficients and biodegradation rates estimated and assigned to Hexane12, Hexane13, and Hexane $13^{*}$ for the mathematical simulations are shown in Table 3.

Table 3: Parameter values assigned to hexane subspecies for the simulations

\begin{tabular}{cc} 
parameter & value \\
\hline Diffusion coefficient $\left(\mathrm{md}^{-1}\right)$ & \\
Hexane12 & \\
Hexane 13 & $0.067[11]$ \\
Hexane13* & $0.0699[8]$ \\
Biodegradation Rate $\left(\mathrm{d}^{-1}\right)$ & $0.0699[8]$ \\
Hexane12 & \\
Hexane 13 & $0.054[6]$ \\
Hexane13* & $0.0534[8]$ \\
\hline
\end{tabular}

\section{RESULTS AND DISCUSSION}

The isotopic fractionation as a function of the distance from the source zone and time was calculated for both experiment and simulation as the ${ }^{13} \mathrm{C}$ enrichment factor $\left(\delta^{13} \mathrm{C}\right)$ according to the following equation:

$\delta^{13} \mathrm{C}=((\mathrm{R} / \mathrm{R} \text { ref })-1)^{*} 1000$ 
where $R$ ref $=0.011237$, and $R$ (for a given time and distance) is calculated as:

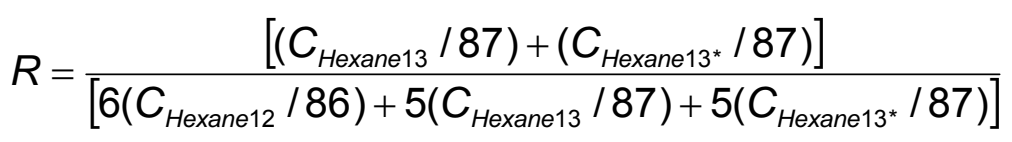

where $C$ is the concentration at the specific time and distance from the source.

Numerical simulation allowed distinguishing and quantifying the effects of slower diffusion or slower biodegradation of ${ }^{13} \mathrm{C}$ fraction of Hexane during transport in the unsaturated zone. The time duration of the simulations was 114 days. The contribution of each one of these processes to the spatial and temporal Hexane fractionation is shown in Figure 2. Figure 2 indicates that both diffusion and biodegradation (individual effect) lead to greater $\delta^{13} \mathrm{C}$ compared to the initial isotope ratio within and close to the contaminant source because both processes cause the lighter isotopes to leave the source faster. As the distance from the source increases, biodegradation leads to enrichment in ${ }^{13} \mathrm{C}$, which is a result of the slightly faster biodegradation of molecules with lighter isotopes, while diffusion results in smaller ${ }^{13} \mathrm{C} /{ }^{12} \mathrm{C}$ ratio as a result of the slightly faster diffusion of molecules with lighter isotopes. The above effects of both processes on the isotope ratio are found to be more pronounced as time increases.

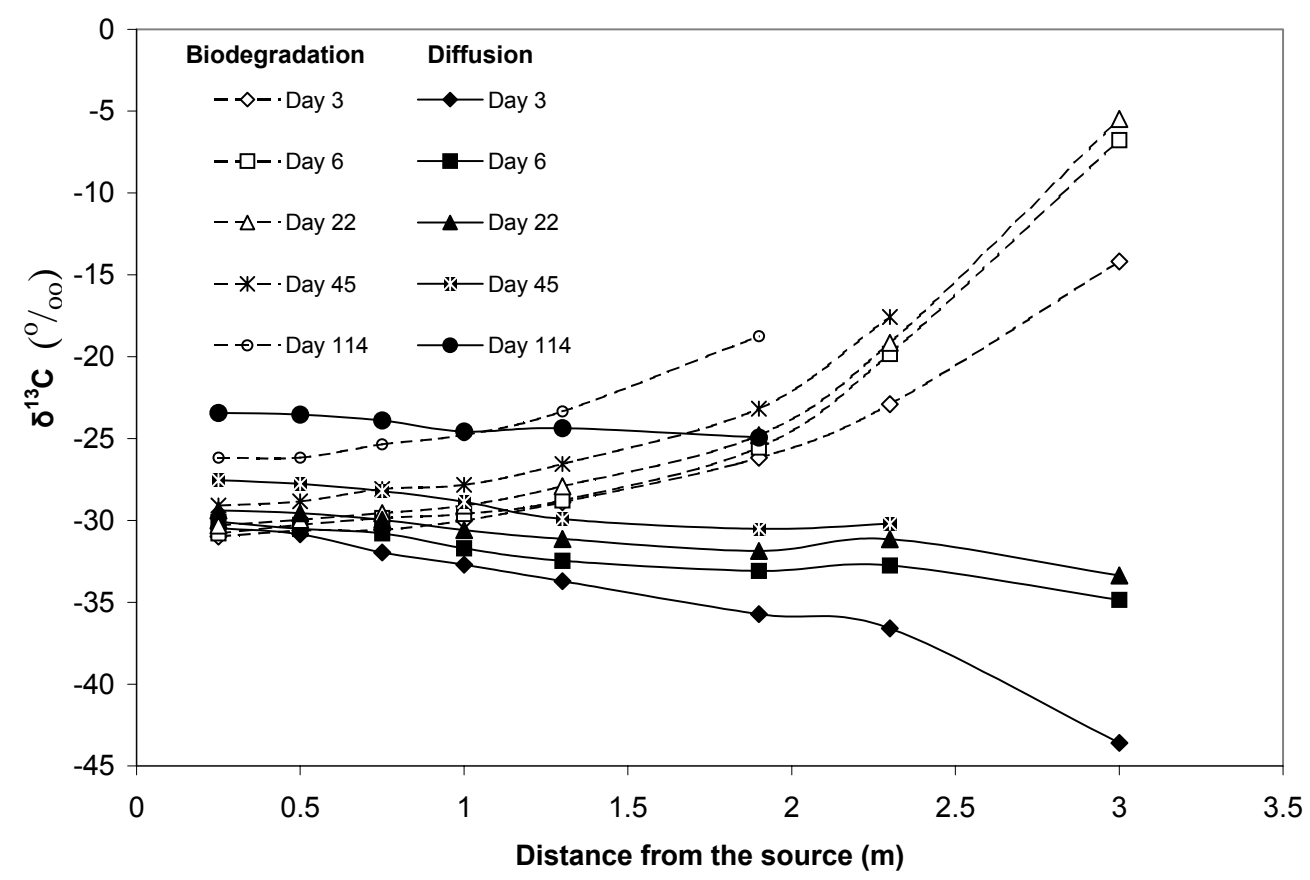

Figure 2. The effects of diffusion and biodegradation on the spatial and temporal carbon isotope fractionation of Hexane during transport in the unsaturated zone

In field applications, it is usually difficult, time consuming, and expensive to prove the occurrence of biodegradation at a contaminated site. It requires extensive monitoring and sampling (e.g., $\mathrm{CO}_{2}, \mathrm{O}_{2}$, VOC concentrations, biodegradation byproducts) for a long period of time. However, the above results show that measuring and modelling the spatial and temporal carbon isotope fractionation of VOCs at a small area around the contaminant source in the unsaturated zone may offer a potential cost effective tool for proving the occurrence of biodegradation and justifying a possible "no action alternative" for a contamination problem. 
The modeled combined effect of diffusion and biodegradation when compared to the field data at the experimental site showed a close agreement (Figure 3). As it is shown in Figure 3 when compared to Figure 2, the occurrence of the biodegradation process at the field site is apparent. These results indicate that monitoring and modeling carbon isotope fractionation of volatile organic compounds near the contaminant source, as described in this study, may represent an effective tool for a fast and relatively inexpensive assessment of biodegradation at contaminated sites.

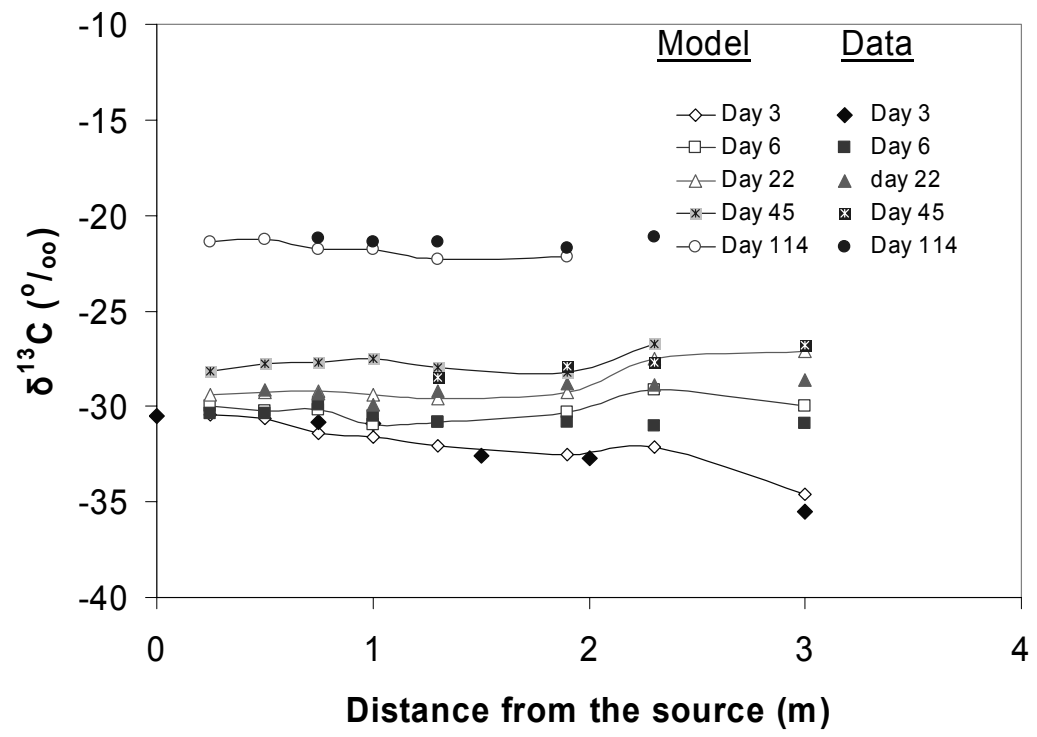

Figure 3. The combined effect of diffusion and biodegradation on the spatial and temporal carbon isotope fractionation of Hexane compared to field data

An experimental and modelling study is currently underway to evaluate biodegradation using field data and carbon isotope enrichment factors found in field and laboratory experiments for a number of volatile organic compounds.

\section{CONCLUSIONS}

Modelling the spatial and temporal trends of carbon isotope fractionation of Hexane in a VOC mixture in the unsaturated zone indicated that (i) both diffusion and biodegradation lead to enrichment in ${ }^{13} \mathrm{C}$ compared to the initial isotope ratio in locations within and close to the contaminant source, (ii) biodegradation lead to enrichment in ${ }^{13} \mathrm{C}$ while diffusion resulted in smaller ${ }^{13} \mathrm{C} /{ }^{12} \mathrm{C}$ ratio in locations further away from the source, and (iii) the above effect of both processes on the isotope ratio was increased as a function of time. Modelling results showed that the use of carbon isotope fractionation at the field represents a promising tool for assessing and possibly quantifying biodegradation of organic contaminants in the unsaturated zone.

\section{REFERENCES}

1. Gaganis P.,. Karapanagioti H. and K., Burganos V. P. (2002), 'Modelling Multicomponent NAPL Transport in the Unsaturated zone with the Constituent Averaging Technique', Adv. Water Resour., 25, 723-732.

2. Hers I., Atwater, J., Li, L. and Zapf-Gilje R. (2000), 'Evaluation of vadose zone biodegradation of BTX vapours', J. Contam. Hydrol., 46, 233-264.

3. Lahvis M.A., Baehr A.L. and Baker R.J. (1999), 'Quantification of aerobic biodegradation and volatilization rates of gasoline hydrocarbons near the water table under natural attenuation conditions', Water Resour. Res., 35, 753-765.

4. Höhener P., Duwig C., Pasteris G., Kaufmann, K., Dakhel N. and Harms H. (2003), 'Biodegradation of petroleum hydrocarbon vapors: laboratory studies on rates and kinetics in unsaturated alluvial sand', Journal of Contaminant Hydrology, 66, 93-115. 
5. Kjeldsen P., Christophersen M., Broholm M., Höhener P., Aravena R. and Hunkeler D. (2003), 'Biodegradation of fuel vapours in the vadose zone at Airbase Værløse, Denmark', 2nd International Workshop on Groundwater Risk Assessment at Contaminated sites and Integrated Soil and Water Protection, March 20-21 2003. TGA, C69, Tübingen, Germany.

6. Gaganis P., Kjeldsen P. and Burganos V. P. (2004), 'Modeling natural attenuation of multicomponent fuel mixtures in the vadose zone: Use of field data and evaluation of biodegradation effects', Vadose Zone Journal, 3, 1262-1275.

7. Katyal A.K., Kaluarachchi, J.J. and Parker J.C. (1991), 'MOFAT: A two-dimensional finite element program for multiphase flow and multicomponent transport', USEPA/600/2-91/020.

8. Bouchard D., Hunkeler D., Höhener P., Aravena R., Broholm M., Kjeldsen P. (2005), 'Use of stable isotope analysis to assess biodegradation of petroleum hydrocarbons in the unsaturated zone. Laboratory studies, field studies, and mathematical simulations', In: Nützmann G, Viotti P, Aagaard P (eds), Reactive Transport in Soil and Groundwater: Processes and Models, Springer, Berlin, pp 17-38.

9. Bouchard D., Hunkeler D., Höhener P., Aravena R., Broholm M. and Kjeldsen, P., (2004), 'Use of stable isotope analysis to assess aerobic biodegradation of aliphatic, alicyclic and aromatic compounds in the unsaturated zone. Laboratory and field study',Proceedings of Workshop "Saturated and unsaturated zone: Integration of process knowledge into effective models", Rome May 5-7, Rome, pp. 77-80.

10. Cerling, Thure E., Kip S.D., Quade J. and Bowman, J. R., (1991), 'On the isotopic composition of carbon in soil carbon dioxide', Geochimica et Cosmochimica Acta, 55(11), 3403-3405.

11. Werner D., Broholm M. and Höhener P. (2005), 'Simultaneous Estimation of Diffusive Volatile Organic Compound (VOC) Fluxes and Non-Aqueous Phase Liquid (NAPL) Saturation in the Vadose Zone', Ground Water Monitoring and Remediation, 25(2), 59-67. 